\title{
Preliminary study on the influence of UV-C irradiation on microorganism viability and polyphenol compounds content during winemaking of 'Regent' red grape cultivar
}

\author{
Kamila Mijowska, ${ }^{1, *}$ Krzysztof Cendrowski, ${ }^{2, *}$ Bartłomiej Grygorcewicz ${ }^{3}$, Jan Oszmiański ${ }^{4}$, \\ Paweł Nawrotek ${ }^{3}$, Ireneusz Ochmian', Beata Zielińska ${ }^{2}$ \\ ${ }^{1}$ West Pomeranian University of Technology, Szczecin, Department of Horticulture, Faculty of Environmental Management \\ and Agriculture, Juliusza Stowackiego 17, 71-434 Szczecin, Poland \\ ${ }^{2}$ West Pomeranian University of Technology, Szczecin, Nanomaterials Physicochemistry Department, Faculty of Chemical \\ Technology and Engineering, Piastów 45, 70-311 Szczecin, Poland \\ ${ }^{3}$ West Pomeranian University of Technology, Szczecin, Department of Immunology, Microbiology and Physiological \\ Chemistry, Faculty of Biotechnology and Animal Husbandry, Piastów 45, 70-311 Szczecin, Poland \\ ${ }^{4}$ Wroctaw University of Environmental and Life Sciences, Department of Fruit, Vegetable and Plant Nutraceutical \\ Technology, Faculty of Biotechnology and Food Science, Chetmońskiego 37, 51-630 Wroctaw, Poland \\ "Corresponding authors: e-mail: krzysztof.cendrowski@zut.edu.pl; kamila.mijowska@zut.edu.pl
}

\begin{abstract}
In this study, UV-C light was tested as an alternative method to inactivate microorganisms in the must of 'Regent' red grape cultivar. The control sample containing the microorganism diluted in a physiological $\mathrm{NaCl}$ solution was prepared to take into consideration different conditions of liquids, such as turbidity and colour. Additionally, the changes in the composition of polyphenol compounds in the 'Regent' must after UV-C exposure were evaluated. The viability of yeasts (Saccharomyces cerevisiae) and bacteria (Oenococcus oeni) significantly decreased with time; however, the highest decline was noted after the first hour of exposure. The polyphenol compound content was significantly lower after UV-C treatment and this was mainly the result of anthocyanin decomposition. The total content of flavan-3-ols and hydroxycinnamic acids and derivatives increased after irradiation.
\end{abstract}

Keywords: UV-C, Oenococcus oeni, Saccharomyces cerevisiae, polyphenol compounds, UPLC-PDA/MS.

\section{INTRODUCTION}

Sulphur dioxide $\left(\mathrm{SO}_{2}\right)$ is commonly used as a preservative in various branches of the food industry, especially in low-pH foods, such as fruit juices and fermentable beverages ${ }^{1}$. Moreover, $\mathrm{SO}_{2}$ in different forms of inorganic sulphites has been widely used in the wine industry to protect against oxidation and the growth of undesired species of yeasts and bacteria and to control enzymatic reactions during wine production and storage ${ }^{2}$. However, allergies caused by $\mathrm{SO}_{2}$-derived compounds are becoming more frequent, causing symptoms such as headaches, nausea, gastric irritation, and breathing difficulties in asthma patients. Consequently, the legislated maximum concentration of $\mathrm{SO}_{2}$ allowed in wines has been gradually reduced ${ }^{1}$. Besides the legislative rules, consumers are becoming much more health conscious and, as a result, prefer healthy products free from chemical additives $^{3}$. As a result, researchers and the wine industry are looking for innovative methods that can reduce or even eliminate the use of $\mathrm{SO}_{2}$ as a preservative without significantly changing the quality of wine $e^{1,3-5}$. Discontinuation of the use of $\mathrm{SO}_{2}$ as an antimicrobial agent without an alternative would increase the risk of wine being spoiled by fungi, yeasts and bacteria. Therefore, it is important to continue the search for alternatives to $\mathrm{SO}_{2}$ preservation to ensure a "clean and green" product that will comply with consumer demands ${ }^{4}$. There have been some studies on the reduction or replacement of $\mathrm{SO}_{2}$ in winemaking; with regard to the production of organic wine, alternatives have been sought that use a substitute products, radiation or electrochemical treatment ${ }^{6}$. Other techniques, such as filtration and fining, are also efficient in controlling microbial growth, but unfortunately, these techniques have detrimental effects on the sensory properties of the wine ${ }^{5}$.

The antimicrobial effect of UV light has been known for a long time, and it can be used in food technology for the disinfection of water, the surfaces of fresh produce or egg shell surfaces, and liquids such as fruit juice, apple cider or milk ${ }^{7-9}$. Moreover, UV light irradiation has a positive consumer image and is of interest to the food industry as a low-cost and non-thermal method of preservation $^{7}$. The UV of wavelengths between 200 and $280 \mathrm{~nm}$ is classified as UV-C and is effective for the inactivation of many microorganisms such as bacteria, viruses, protozoa, yeasts, moulds and algae ${ }^{9-10}$. UV-C radiation is one of the emerging techniques for the inactivation of microorganisms in liquid food products, and it also holds considerable promise for the treatment of wine. This application can be of particular interest to reduce or even eliminate the use of $\mathrm{SO}_{2}$ as a preservative in winemaking, given its potential health risks ${ }^{3,5}$.

The aim of this paper is to evaluate the impact of UV-C radiation on the viability of yeast (Saccharomyces cerevisiae) and bacteria (Oenococcus oeni) in fermenting juice of the 'Regent' grape cultivar and in physiological $\mathrm{NaCl}$ solution. Furthermore, the article describes changes in the qualitative and quantitative composition of polyphenol compounds in the 'Regent' must after UV-C exposure.

\section{MATERIAL AND METHODS}

\section{Must preparation}

Grapes from the 'Regent' red cultivar were cultivated at a research station of the West Pomeranian University 
of Technology, Szczecin (Poland). After the harvest, all fruit was kept frozen until the beginning of the experiment. The strains used in this study were the commercial Saccharomyces cerevisiae (VQ Assmanshausen) and Oenococcus oeni (DSM7008) from VINIFLORA $® O E N O S$ (CHR HANSEN). After the grapes had been thawed, $0.1 \mathrm{~g} / \mathrm{L}$ of $\mathrm{SO}_{2}$ was added to eliminate unwanted microorganisms before inoculation with commercial yeast (Saccharomyces cerevisiae). The dry active wine yeast $(30 \mathrm{~g} / \mathrm{hL})$ was prepared with $150 \mathrm{~mL}$ of water at $35^{\circ} \mathrm{C}$ and added to the grape must. Oenococcus oeni was used in this study as a typical bacteria to performed malolactic fermentation. Inoculation of the grape must with bacteria was performed three weeks after the initiation of alcoholic fermentation. After five days of bacteria adaptation, UV-C treatment was conducted. Samples of must for the experiment were taken from above the sediment and cleared off the mess part.

\section{Preparation of microorganism suspension}

The Oenococcus oeni and Saccharomyces cerevisiae were cultured at $30^{\circ} \mathrm{C}$ in de Mann, Rogosa and Sharpe broth (MRS, Emapol, Gdańsk, Poland) and Yeast extract Peptone Dextrose (YPD, Emapol, Gdańsk, Poland), respectively. When the turbidity of the Oenococcus oeni or Saccharomyces cerevisiae culture reached an optical density at $600 \mathrm{~nm}=0.8$, the requested volume was centrifuged. Cells were washed three times with a physiological $\mathrm{NaCl}$ solution $(0.85 \%)$ and re-suspended in $0.85 \% \mathrm{NaCl}$ to reach the cell density of approximately $3.00 \times 10^{6} \mathrm{CFU} / \mathrm{mL}$.

\section{UV-C treatment}

The samples of fermenting must and the physiological $\mathrm{NaCl}$ solution containing microorganisms were separately subjected to irradiation with UV-C. The reactions were carried out in an inner-irradiation-type reactor equipped with a low-pressure $15 \mathrm{~W}$ mercury lamp $(254 \mathrm{~nm})$ and a cooling jacket to avoid sample heating (Fig. 1). In a typical experiment, $500 \mathrm{~mL}$ of the sample was stirred using a magnetic stirrer, which is sufficient to ensure equal exposure of all fluid elements ${ }^{11}$. All samples were irradiated with UV-C light for 180 minutes. Doses (10

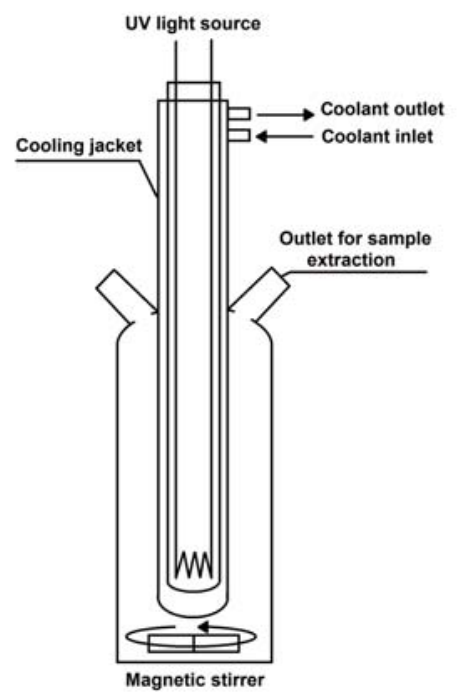

Figure 1. The inner-irradiation-type UV-C reactor equipped with a low-pressure mercury lamp of $15 \mathrm{~W}(254 \mathrm{~nm})$
$\mathrm{mL}$ ) of the reaction mixture were taken at regular time intervals $(0,60,120$ and 180 minutes) during each process to determine yeast and bacteria viabilities as well as polyphenol content in the grape must. Samples taken at 0 minutes served as controls. All reactions were conducted in duplicate.

\section{Post-treatment analyses}

\section{Microbiological tests}

Microbiological tests were performed immediately after the UV-C treatment of the grape must and the physiological $\mathrm{NaCl}$ solution containing microorganisms. The remaining parts of each $10 \mathrm{~mL}$ dose taken from treated samples were left for another 48 hours. After two days, microbiological tests were repeated. Once again, the experimental samples were collected from above the sediment, which is usually removed during the winemaking process. Three replicates of each combination were performed.

To determine the number of viable bacteria and yeasts in the samples, decimal dilutions were made in PBS $\left(135 \mathrm{mM} \mathrm{NaCl}, 1.3 \mathrm{mM} \mathrm{KCl}, 0.5 \mathrm{mM} \mathrm{KH}_{2} \mathrm{PO}_{4}, 3.2 \mathrm{mM}\right.$ $\mathrm{Na}_{2} \mathrm{HPO}_{4}, \mathrm{pH}$ 7.4) and plated. The Saccharomyces cerevisiae was maintained at $25^{\circ} \mathrm{C}$ using Sabouraud Dextrose Agar (SDA, Emapol, Gdańsk, Poland) supplemented with chloramphenicol $(0.05 \mathrm{~g} / \mathrm{L})$. The Oenococcus oeni was cultured at $25^{\circ} \mathrm{C}$ using MRS Agar supplemented with cycloheximide $(0.1 \mathrm{~g} / \mathrm{L})$.

\section{Polyphenol compounds determination}

The samples were filtered through a $0.22-\mu \mathrm{m}$-membrane filter before analysis ${ }^{12}$. Measurement of phenolic compounds was performed by the UPLC-PDA-MS method ${ }^{13}$. In the 'Regent' grape juice, polyphenol identification was executed by using an ACQUITY Ultra Performance LC system appointed with a binary solvent manager, a photodiode array detector (Waters Corporation, Milford, MA, USA) and a G2 Q-TOF micro mass spectrometer (Waters, Manchester, UK) equipped with an electrospray ionisation (ESI) source operating in both negative and positive modes. Individual polyphenol separations were executed using a UPLC BEH C18 column $(1.7 \mu \mathrm{m}, 2.1$ $\mathrm{mm} \times 100 \mathrm{~mm}$, Waters Corporation, Milford, MA). The experiment was conducted in duplicate.

\section{Statistical analysis}

All statistical analyses were performed with Statistica 12.5 (StatSoft Polska, Cracow, Poland). The data were subjected to one-factor variance analysis (ANOVA). Mean comparisons were performed using Tukey's least significant difference (LSD) test; significance was set at $\mathrm{p}<0.05$.

\section{RESULTS}

\section{Evaluation of microorganism viability}

The efficiency of UV-C light to inactivate co-inoculated Saccharomyces cerevisiae and Oenococcus oeni in the fermenting grape juice was determined. The study was based on the juice of the dark red grape cultivar 'Regent'. Thereupon, a control samples of the transparent physiological $\mathrm{NaCl}$ solution containing microorganisms 
without organic compounds was prepared to take into consideration the different properties of the two liquids such as turbidity and colour. Additionally, the effect on microorganism viability of stirring the fermenting grape must without UV-C irradiation was studied. Figure 2 shows the changes in microorganism viability (Saccharomyces cerevisiae, Oenococcus oeni) in the 'Regent' must under hour-long stirring with and without UV-C irradiation in terms of initial microbial counts. It is clearly shown that microorganism viability was not greatly affected by stirring. However, UV-C light had a significant impact, decreasing the counts in yeast and bacteria cultures.

To evaluate the effect of UV-C irradiation on microorganism viability, microbiological analyses were carried out before and after UV-C treatment. Figures 3 and 4 show the counts of live yeast (Saccharomyces cerevisiae) and bacteria (Oenococcus oeni) cells in the grape must and in the $\mathrm{NaCl}$ solution after 60,120 and 180 minutes of UV-C irradiation and their relative number related to the initial counts $(0-$ control $)$ expressed as $\mathrm{CFU} / \mathrm{mL}$ and $\%$, respectively. Figures 3 and 4 contain the results
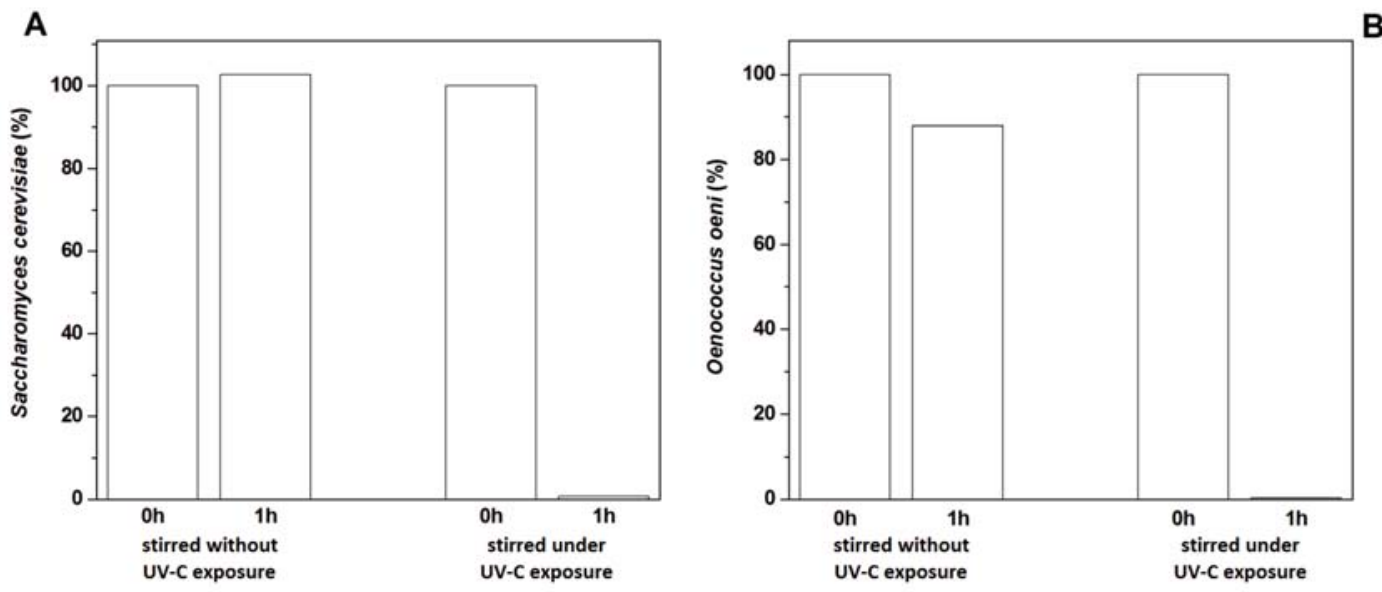

Figure 2. Changes of the microorganism viability (Saccharomyces cerevisiae, Oenococcus oeni) in fermenting must of 'Regent' under stirring with and without UV-C irradiation

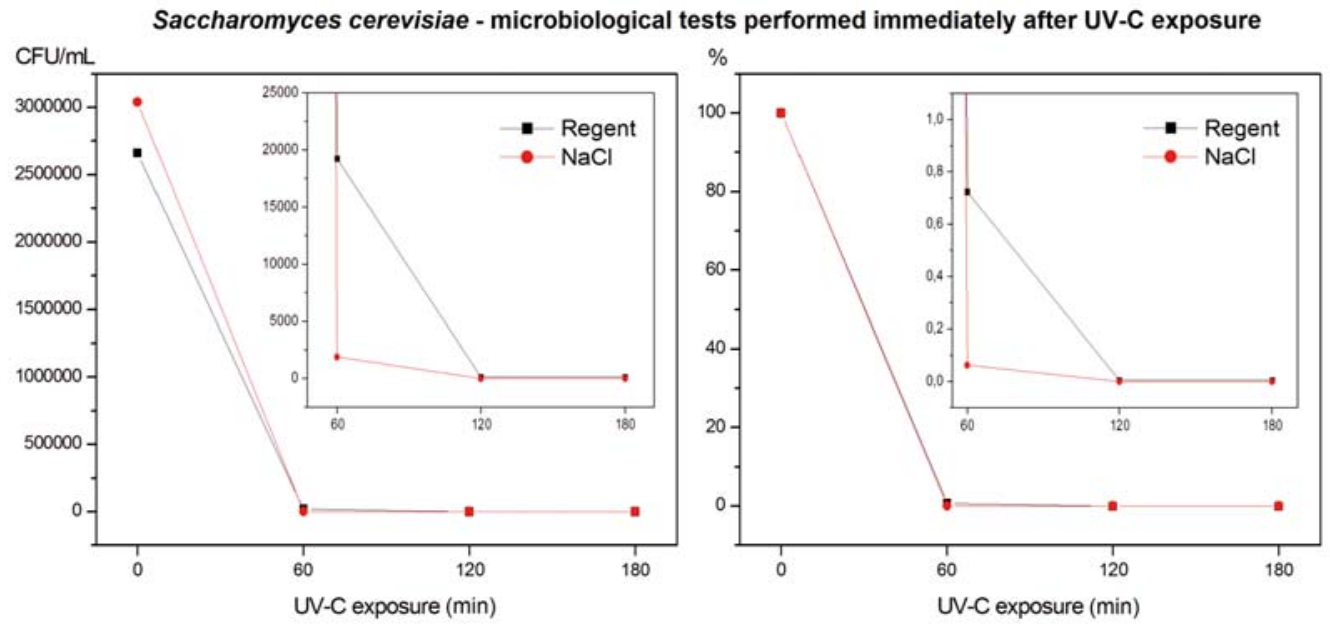

Saccharomyces cerevisiae - microbiological tests performed 48 hours after UV-C exposure
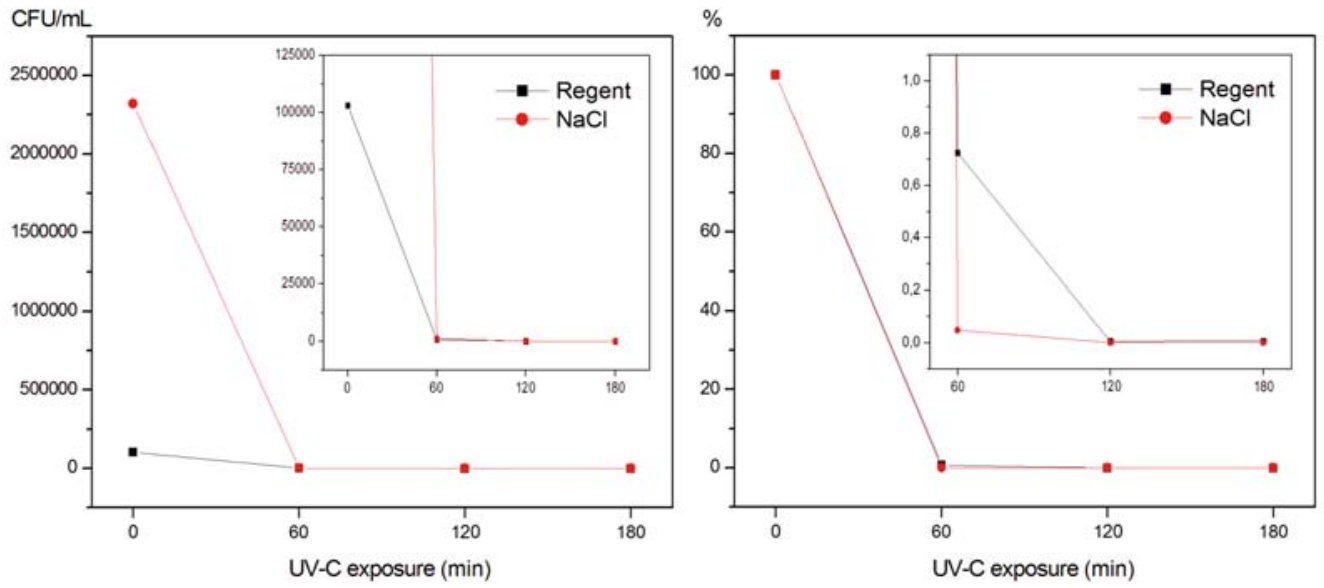

Figure 3. Saccharomyces cerevisiae live cells in fermenting must of 'Regent' and $\mathrm{NaCl}$ solution after UV-C irradiation (60, 120,180 minutes) and compare to initial counts $(0-$ control $)$, expressed as $\mathrm{CFU} / \mathrm{mL}$ and $\%$. The inset shows specified range of colony-forming unit 
of microbial tests performed immediately and 48 hours after irradiation. The average initial counts of Saccharomyces cerevisiae in the grape must and $\mathrm{NaCl}$ solution were $2.66 \times 10^{6}$ and $3.04 \times 10^{6} \mathrm{CFU} / \mathrm{mL}$, respectively (Fig. 3). The average initial counts of Oenococcus oeni in the grape must and the $\mathrm{NaCl}$ solution were $5.33 \times 10^{5}$ and $3.00 \times 10^{6} \mathrm{CFU} / \mathrm{mL}$, respectively (Fig. 4). Significant reductions in yeast and bacteria were observed after irradiation in both the fermenting must and the $\mathrm{NaCl}$ solution. The decrease of microorganism viability was correlated with the increase in the ultraviolet exposure time. However, for all samples, the highest decline of live microbial cells, approximately $99 \%$, was noticed after 60 minutes of UV-C radiation. Nevertheless, hour-long treatment was not sufficient to eliminate yeasts and bacteria completely: after hour-long treatment, the viability of Saccharomyces cerevisiae in the grape must and $\mathrm{NaCl}$ solution was reduced to $1.93 \times 10^{4}$ and 1.90 $\times 10^{3} \mathrm{CFU} / \mathrm{mL}$, respectively (Fig. 3 ), and the viability of Oenococcus oeni was reduced to $1.52 \times 10^{3}$ and $1.15 \times$ $10^{3} \mathrm{CFU} / \mathrm{mL}$ in fermenting juice and $\mathrm{NaCl}$, respectively (Fig. 4). However, it should be emphasised, that in the case of bacteria, the initial counts varied enormously between samples. Two hours of UV treatment enabled reduction to $1.42 \times 10^{2}$ and $1.58 \times 10^{1} \mathrm{CFU} / \mathrm{mL}$ in the grape must for yeasts and bacteria, respectively. Here, one can notice that UV-C irradiation had a greater impact on the viability of Oenococcus oeni than of Saccharomyces cerevisiae. Furthermore, there were differences in the effectiveness of UV radiation on dark and light solutions. It was found that UV-C irradiation was slightly more efficient in the $\mathrm{NaCl}$ solution, where microorganisms were eliminated completely after 180 minutes. The tests performed 48 hours after UV-C treatment showed that the viability of microorganisms decreased rapidly in all samples, especially in those of the 'Regent' juice, and this was the result of sedimentation. However, the irradiated grape must and $\mathrm{NaCl}$ solution, still contained significantly fewer live cells than the untreated samples. The results of microbiological tests performed 48 hours after experiment with UV-C exposure showed that microbial counts in the 'Regent' juice control were 1.03 $\times 10^{5}$ and $2.07 \times 10^{4} \mathrm{CFU} / \mathrm{mL}$ for yeasts and bacteria, respectively, while the results after hour-long treatment were $7.47 \times 10^{2}$ and $5.89 \times 10^{1} \mathrm{CFU} / \mathrm{mL}$ for yeasts and bacteria, respectively.

\section{Polyphenols}

The phenolic compounds were determined in the 'Regent' juice of examined samples by retention time using ultra-pressure liquid chromatography with the photodiode array and mass spectrometry (UPLC-PDA/ MS). The results are presented in Table 1.

Figure 5 shows changes in the polyphenol content in the 'Regent' must in relation to the UV-C exposure time and control. The results clearly indicate that increasing the UV-C exposure time led to significant decrease in the polyphenol content. The highest total polyphenol
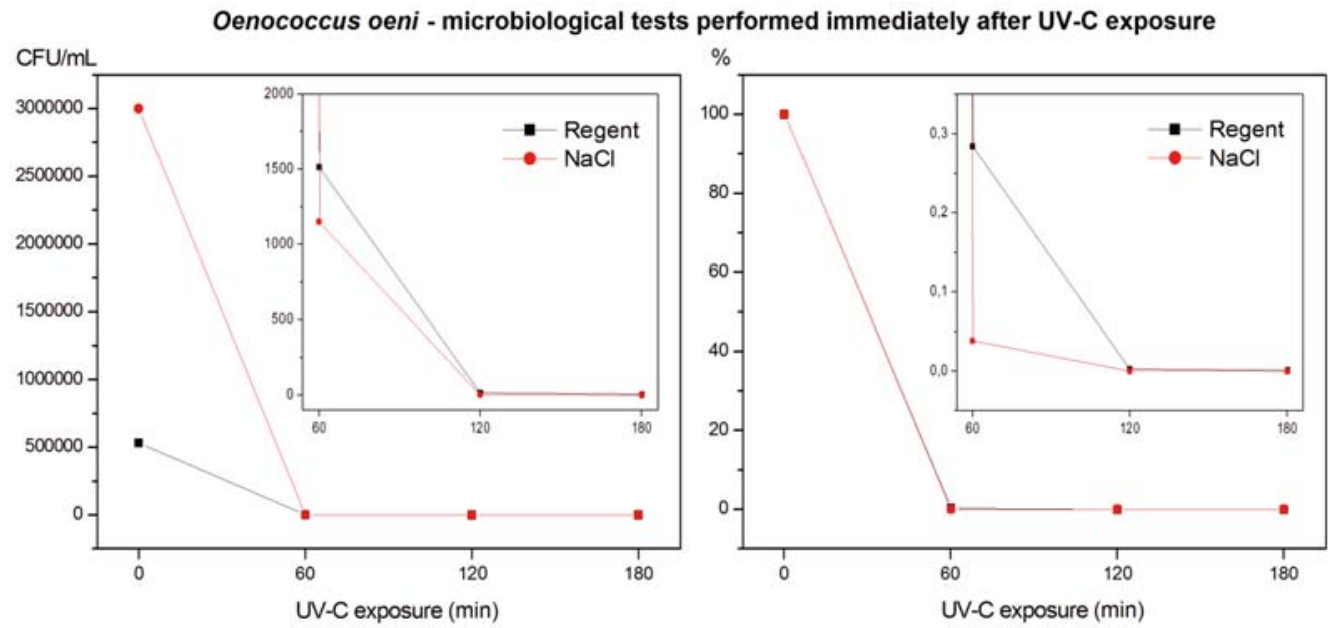

Oenococcus oeni - microbiological tests performed 48 hours after UV-C exposure
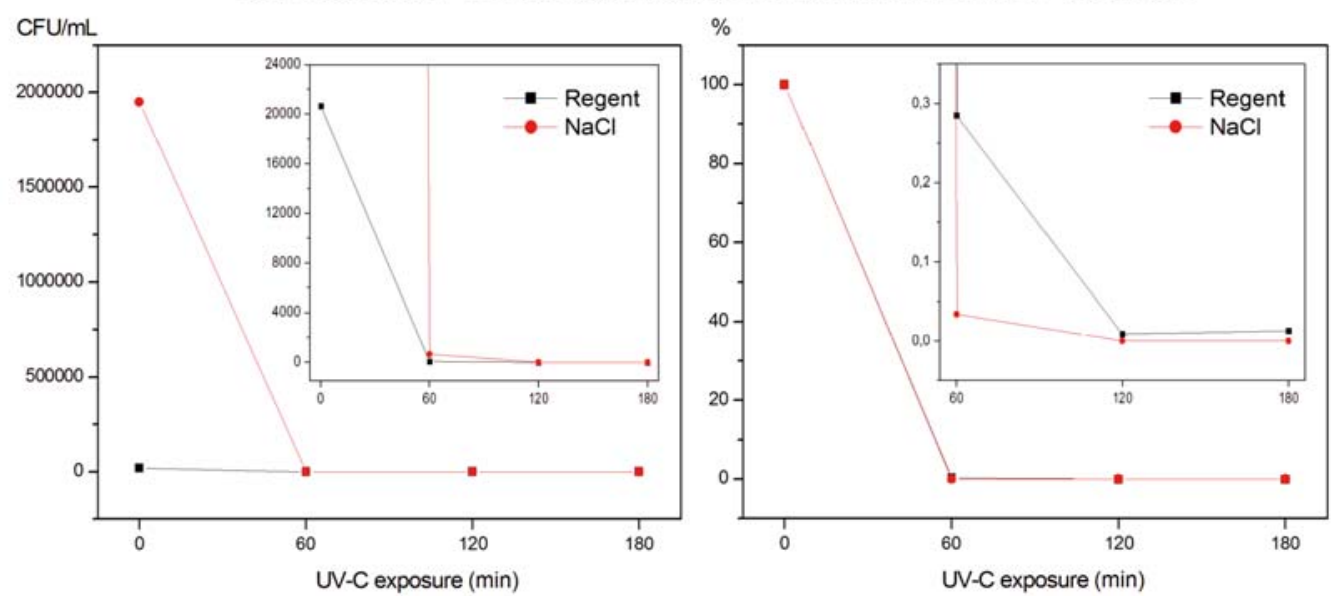

Figure 4. Oenococcus oeni live cells in fermenting must of 'Regent' and $\mathrm{NaCl}$ solution after UV-C irradiation (60, 120, 180 minutes) and compare to initial counts $(0-$ control), expressed as CFU/mL and \%. The inset shows specified range of colonyforming unit 
Table 1. The identification of phenolic compounds of 'Regent' must by retention time using their spectral characteristics in ultra-pressure liquid chromatography with photodiode array and mass spectrometry (UPLC-PDA/ MS)

\begin{tabular}{|l|c|c|}
\hline Compounds & $\begin{array}{c}\mathrm{Tr} \\
\text { [min] }\end{array}$ & $\mathrm{MS}$ \\
\hline Gallic acid & 0.87 & 167 \\
\hline Delphinidin 3.5-diGlc & 2.43 & 627 \\
\hline GRP (cis- and trans- isomers) & 2.55 & 616 \\
\hline Caftaric acid (cis- and trans- isomers) & 2.63 & 311 \\
\hline Caftaric acid (cis- and trans- isomers) & 2.78 & 311 \\
\hline Coutaric acid (cis- and trans- isomers) & 2.92 & 295 \\
\hline Cyanidin 3.5-diGlc;Petunidin 3.5-diGlc & 2.93 & $641 ; 611$ \\
\hline Delphinidin 3-O-Glc & 3.23 & 465 \\
\hline (+)-Catechin & 3.38 & 289 \\
\hline Peonidin 3.5-diGlc;Malvidin 3.5-diGlc & 3.63 & $625 ; 655$ \\
\hline Coutaric acid (cis- and trans- isomers) & 3.80 & 295 \\
\hline Fertaric acid & 3.86 & 325 \\
\hline Petunidin 3-O-Glc & 4.02 & 479 \\
\hline Dimer B2 & 4.13 & 577 \\
\hline (-)-Epicatechin & 4.24 & 289 \\
\hline Peonidin 3-O-Glc & 4.54 & 463 \\
\hline Malvidin 3-O-Glc & 4.72 & 493 \\
\hline Myricetin Glc & 5.20 & 479 \\
\hline Myricetin glucuronide & 5.20 & 493 \\
\hline Delphinidin 3-O-acetyl-Glc & 5.23 & 507 \\
\hline Cyanidin 3-O-acetyl-Glc & 5.69 & 491 \\
\hline Petunidin 3-O-acetyl-Glc & 5.86 & 521 \\
\hline Quercetin-3-O-glu & 6.05 & 463 \\
\hline $\begin{array}{l}\text { (epi)cat-ethyl-malvidin 3-O-Glc } \\
\text { (isomer) }\end{array}$ & 6.05 & 809 \\
\hline Quercetin glucuronide & 6.17 & 477 \\
\hline $\begin{array}{l}\text { (epi)cat-ethyl-malvidin 3-O-Glc } \\
\text { (isomer) }\end{array}$ & 6.33 & 809 \\
\hline $\begin{array}{l}\text { (epi)cat-ethyl-malvidin 3-O-Glc } \\
\text { (isomer) }\end{array}$ & 6.54 & 809 \\
\hline Cyanidin 3-O-coumaroyl-Glc & 7.06 & 595 \\
\hline Petunidin 3O-coumaroy+Glc & 7.16 & 625 \\
\hline Malvidin 3-O-coumaroyl-Glc & 7.73 & 639 \\
\hline Quercetin & 8.60 & 301 \\
\hline & & \\
\hline
\end{tabular}

value - $1235.48 \mathrm{mg} 100 \mathrm{~g}^{-1} \mathrm{FW}$ - was in the untreated sample (control), followed by that in samples after 60, 120 and 180 minutes of UV-C exposure: 1159.93,

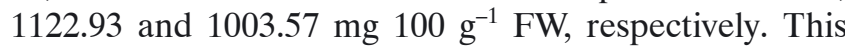
means that the reduction in polyphenol compounds was

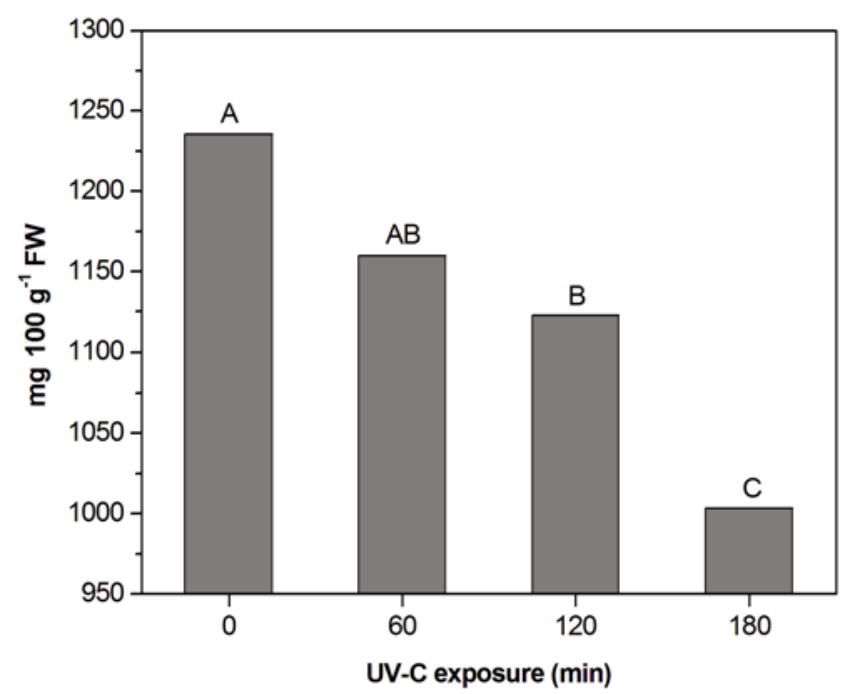

Figure 5. The polyphenol content in red must of 'Regent' (mg $100 \mathrm{~g}^{-1}$ FW) after UV-C irradiation $(60,120,180$ minutes) and compare to initial counts $(0-$ control $)$. Means having same letter were not significantly different by Tukey's comparison $\mathrm{p}<0.05$ level approximately $19 \%$ after 180 minutes of treatment. The results showed changes in the quantitative composition of polyphenol compounds in the grape must, but no differences in the qualitative composition of the samples between treatments.

The decreased polyphenol content in the 'Regent' grape must was caused mainly by anthocyanin decomposition. Table 2 shows changes in the anthocyanin content in the 'Regent' must relative to the UV-C exposure time and control. There were $575.20 \mathrm{mg} 100 \mathrm{~g}^{-1} \mathrm{FW}$ of anthocyanin compounds in the untreated sample. After three hours of UV-C treatment, the anthocyanin content was reduced to $282.79 \mathrm{mg} 100 \mathrm{~g} \mathrm{~g}^{-1} \mathrm{FW}$, which was approximately $51 \%$ lower than in the control. However, UV exposure did not adversely affect the colour of the sample. Derivatives of delphinidin, cyanidin, petunidin, peonidin and malvidin were identified as anthocyanins. All compounds showed a significant decrease in amount with an increase in the treatment time. In the context of the quantitative composition, peonidin 3.5-diGlc and malvidin 3.5-diGlc compounds showed the highest decline after three hours of UV-C exposure. However, when the decline is considered in percentage terms, the greatest change observed was for petunidin 3-O-coumaroyl-Glc, which was reduced by nearly $70 \%$ after three hours of irradiation. The hour-long treatment showed no statistical influence on the content of delphinidin 3.5-diGlc, cyanidin 3.5-diGlc; petunidin 3.5-diGlc, peonidin 3-O-Glc and (epi) cat-ethyl-malvidin 3-O-Glc (isomer) - Tr 6.05 and 6.33.

GRP (cis- and trans- isomers), caftaric acid (cis- and trans- isomers), coutaric acid (cis- and trans- isomers) and fertaric acid belonging to hydroxycinnamic acids and derivatives were identified in the 'Regent' must. The relative changes in their content in the 'Regent' must with UV-C exposure are presented in Table 3. Generally, the content of compounds in this subgroup increased from $418.10 \mathrm{mg} 100 \mathrm{~g}^{-1} \mathrm{FW}$ in the control sample to 423.22 , 467.29 and $471.43 \mathrm{mg} 100 \mathrm{~g}^{-1} \mathrm{FW}$ for 60,120 and 180 minutes of treatment, respectively. In more detail, this was caused by the increases in caftaric acid (cis- and trans- isomers) - $\operatorname{Tr} 2.63$, and coutaric acid (cis- and trans- isomers) - Tr 3.80 that were around four and six times higher respectively after a three hour-long UV-C exposure. Other compounds were more stable, especially coutaric acid (cis- and trans- isomers) - $\operatorname{Tr} 2.92$, and fertaric acid, for which no statistical differences were noticed.

The UV-C light had a significant impact on the level of gallic acid in the 'Regent' must (Table 3). There was a statistically relevant decrease in the amount in all treated samples compared to the control. The untreated sample contained $5.49 \mathrm{mg} 100 \mathrm{~g}^{-1} \mathrm{FW}$ of gallic acid, while its content in exposed samples varied from 3.82 to 4.28 mg $100 \mathrm{~g}^{-1}$ FW. Nevertheless, there was no observed difference between the treated samples in terms of the amount of gallic acid.

The results showed no statistical significant influence of UV-C exposure on the total flavonol content in 'Regent' samples (Table 4). The amount of these compounds

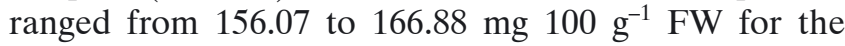
hour-long exposure and the control, respectively. Some relevant differences between the samples occurred in the cases of myricetin glucuronide and quercetin, but without 
Table 2. The anthocyanin content in red must of 'Regent' ( $\mathrm{mg} 100 \mathrm{~g}^{-1} \mathrm{FW}$ ) as related to different time of UV-C exposition

\begin{tabular}{|l|c|c|c|c|}
\hline \multirow{2}{*}{ Compounds } & \multicolumn{4}{|c|}{ UV-C treatments [min] $^{*}$} \\
\cline { 2 - 5 } & 0 & 60 & 120 & 180 \\
\hline Delphinidin 3.5-diGlc & $26.12 \pm 1.42 \mathrm{a}$ & $23.78 \pm 2.12 \mathrm{a}$ & $16.89 \pm 1.51 \mathrm{~b}$ & $10.86 \pm 1.50 \mathrm{c}$ \\
\hline Cyanidin 3.5-diGlc; Petunidin 3.5-diGlc & $51.64 \pm 2.91 \mathrm{a}$ & $46.45 \pm 2.73 \mathrm{a}$ & $38.61 \pm 2.84 \mathrm{~b}$ & $27.52 \pm 2.59 \mathrm{c}$ \\
\hline Delphinidin 3-O-Glc & $35.58 \pm 1.33 \mathrm{a}$ & $27.76 \pm 1.08 \mathrm{~b}$ & $22.84 \pm 1.14 \mathrm{~b}$ & $14.49 \pm 0.95 \mathrm{c}$ \\
\hline Peonidin 3.5-diGlc; Malvidin 3.5-diGlc & $348.44 \pm 11.06 \mathrm{a}$ & $318.85 \pm 14.79 \mathrm{~b}$ & $252.58 \pm 10.12 \mathrm{c}$ & $181.79 \pm 8.94 \mathrm{~d}$ \\
\hline Petunidin 3-O-Glc & $27.53 \pm 0.98 \mathrm{a}$ & $21.03 \pm 1.14 \mathrm{~b}$ & $18.15 \pm 1.21 \mathrm{~b}$ & $11.87 \pm 0.83 \mathrm{c}$ \\
\hline Peonidin 3-O-Glc & $11.46 \pm 0.37 \mathrm{a}$ & $9.44 \pm 0.32 \mathrm{a}$ & $9.85 \pm 0.40 \mathrm{a}$ & $5.32 \pm 0.25 \mathrm{~b}$ \\
\hline Malvidin 3-O-Glc & $51.83 \pm 1.84 \mathrm{a}$ & $40.20 \pm 1.72 \mathrm{~b}$ & $31.74 \pm 1.45 \mathrm{c}$ & $21.24 \pm 1.16 \mathrm{~d}$ \\
\hline Delphinidin 3-O-acetyl-Glc & $1.80 \pm 0.057 \mathrm{a}$ & $1.48 \pm 0.053 \mathrm{~b}$ & $1.48 \pm 0.060 \mathrm{~b}$ & $1.30 \pm 0.049 \mathrm{~b}$ \\
\hline Cyanidin 3-O-acetyl-Glc & $1.96 \pm 0.053 \mathrm{a}$ & $1.36 \pm 0.047 \mathrm{~b}$ & $1.40 \pm 0.045 \mathrm{~b}$ & $0.91 \pm 0.039 \mathrm{c}$ \\
\hline Petunidin 3-O-acetyl-Glc & $2.58 \pm 0.074 \mathrm{a}$ & $1.44 \pm 0.039 \mathrm{bc}$ & $1.67 \pm 0.058 \mathrm{~b}$ & $1.29 \pm 0.046 \mathrm{c}$ \\
\hline (epi)cat-ethyl-malvidin 3-O-Glc (isomer) Tr 6.05 & $1.04 \pm 0.032 \mathrm{a}$ & $1.12 \pm 0.035 \mathrm{a}$ & $0.52 \pm 0.022 \mathrm{~b}$ & $0.38 \pm 0.016 \mathrm{~b}$ \\
\hline (epi)cat-ethyl-malvidin 3-O-Glc (isomer) Tr 6.33 & $1.56 \pm 0.041 \mathrm{a}$ & $1.53 \pm 0.043 \mathrm{a}$ & $1.01 \pm 0.037 \mathrm{~b}$ & $0.71 \pm 0.032 \mathrm{c}$ \\
\hline (epi)cat-ethyl-malvidin 3-O-Glc (isomer) Tr 6.54 & $6.28 \pm 0.19 \mathrm{a}$ & $4.17 \pm 0.15 \mathrm{~b}$ & $3.26 \pm 0.13 \mathrm{c}$ & $2.29 \pm 0.11 \mathrm{~d}$ \\
\hline Cyanidin 3-O-coumaroyl-Glc & $1.29 \pm 0.032 \mathrm{a}$ & $0.95 \pm 0.029 \mathrm{~b}$ & $0.91 \pm 0.030 \mathrm{~b}$ & $0.61 \pm 0.027 \mathrm{c}$ \\
\hline Petunidin 3-O-coumaroyl-Glc & $1.79 \pm 0.039 \mathrm{a}$ & $1.36 \pm 0.041 \mathrm{~b}$ & $1.13 \pm 0.037 \mathrm{c}$ & $0.55 \pm 0.025 \mathrm{~d}$ \\
\hline Malvidin 3-O-coumaroyl-Glc & $4.28 \pm 0.18 \mathrm{a}$ & $3.41 \pm 0.13 \mathrm{~b}$ & $2.87 \pm 0.12 \mathrm{c}$ & $1.69 \pm 0.08 \mathrm{~d}$ \\
\hline Anthocyanins & $\mathbf{5 7 5 . 2 0 A}$ & $\mathbf{5 0 4 . 3 3 \mathrm { B }}$ & $\mathbf{4 0 4 . 9 2 C}$ & $\mathbf{2 8 2 . 7 9 D}$ \\
\hline
\end{tabular}

*UV-C treatments: 0 - untreated sample (control); 60 - an hour of UV-C exposition; 120 - two hours of UV-C exposition; 180 - three hours of UV-C exposition. Means in the same row followed by the same letter are not significantly different at $p<0.05$ according to Tukey test; \pm SD: standard deviation.

Table 3. The gallic acid, hydroxycinnamic acids and derivatives contents in red must of 'Regent' ( $\mathrm{mg}^{100 \mathrm{~g}^{-1}} \mathrm{FW}$ ) as related to different time of UV-C exposition

\begin{tabular}{|l|c|c|c|c|}
\hline \multirow{2}{*}{ Compounds } & \multicolumn{4}{|c|}{ UV-C treatments [min] $^{*}$} \\
\cline { 2 - 5 } & 0 & 60 & 120 & 180 \\
\hline Gallic acid & $\mathbf{5 . 4 9 A}$ & $\mathbf{3 . 8 2 B}$ & $\mathbf{4 . 2 8 B}$ & $\mathbf{4 . 1 2 B}$ \\
\hline GRP (cis- and trans- isomers) & $24.50 \pm 0.78 \mathrm{a}$ & $18.38 \pm 0.70 \mathrm{~b}$ & $22.10 \pm 0.74 \mathrm{a}$ & $21.17 \pm 0.086 \mathrm{ab}$ \\
\hline Caftaric acid (cis- and trans- isomers) $\operatorname{Tr} 2.63$ & $12.50 \pm 0.29 \mathrm{c}$ & $14.18 \pm 0.38 \mathrm{c}$ & $34.49 \pm 1.27 \mathrm{~b}$ & $48.44 \pm 1.79 \mathrm{a}$ \\
\hline Caftaric acid (cis- and trans- isomers) $\operatorname{Tr} 2.78$ & $0.14 \pm 0.001 \mathrm{~b}$ & $0.27 \pm 0.002 \mathrm{a}$ & $0.18 \pm 0.001 \mathrm{~b}$ & $0.13 \pm 0.001 \mathrm{~b}$ \\
\hline Coutaric acid (cis- and trans- isomers) $\operatorname{Tr} 2.92$ & $271.35 \pm 8.33 \mathrm{a}$ & $259.49 \pm 8.02 \mathrm{a}$ & $271.79 \pm 10.85 \mathrm{a}$ & $267.38 \pm 13.66 \mathrm{a}$ \\
\hline Coutaric acid (cis- and trans- isomers) $\operatorname{Tr} 3.80$ & $5.80 \pm 0.15 \mathrm{~b}$ & $31.59 \pm 0.99 \mathrm{a}$ & $34.74 \pm 1.36 \mathrm{a}$ & $33.00 \pm 1.52 \mathrm{a}$ \\
\hline Fertaric acid & $103.81 \pm 2.98 \mathrm{a}$ & $99.32 \pm 3.11 \mathrm{a}$ & $103.99 \pm 3.47 \mathrm{a}$ & $101.32 \pm 4.79 \mathrm{a}$ \\
\hline Hydroxycinnamic acids and derivatives & $\mathbf{4 1 8 . 1 0 B}$ & $\mathbf{4 2 3 . 2 2 B}$ & $\mathbf{4 6 7 . 2 9 A}$ & $\mathbf{4 7 1 . 4 3 A}$ \\
\hline
\end{tabular}

${ }^{*}$ UV-C treatments: 0 - untreated sample (control); 60 - an hour of UV-C exposition; 120 - two hours of UV-C exposition; 180 - three hours of UV-C exposition. Means in the same row followed by the same letter are not significantly different at $p<0.05$ according to Tukey test; \pm SD: standard deviation.

Table 4. The flavonol and flavan-3-ols contents in red must of 'Regent' (mg $100 \mathrm{~g}^{-1} \mathrm{FW}$ ) as related to different time of UV-C exposition

\begin{tabular}{|l|c|c|c|c|}
\hline \multirow{2}{*}{ Compounds } & \multicolumn{4}{|c|}{ UV-C treatments [min] $]^{*}$} \\
\cline { 2 - 5 } & 0 & 60 & 120 & 180 \\
\hline Myricetin Glc & $28.30 \pm 0.54 \mathrm{a}$ & $28.21 \pm 0.83 \mathrm{a}$ & $29.91 \pm 0.94 \mathrm{a}$ & $25.06 \pm 1.09 \mathrm{a}$ \\
\hline Myricetin glucuronide & $2.91 \pm 0.082 \mathrm{~b}$ & $3.14 \pm 0.097 \mathrm{ab}$ & $3.46 \pm 0.12 \mathrm{a}$ & $2.03 \pm 0.10 \mathrm{c}$ \\
\hline Quercetin-3-O-glu & $9.44 \pm 0.27 \mathrm{a}$ & $9.03 \pm 0.30 \mathrm{a}$ & $9.40 \pm 0.34 \mathrm{a}$ & $9.29 \pm 0.36 \mathrm{a}$ \\
\hline Quercetin glucuronide & $116.86 \pm 2.78 \mathrm{a}$ & $109.52 \pm 3.11 \mathrm{a}$ & $114.63 \pm 3.56 \mathrm{a}$ & $115.30 \pm 4.08 \mathrm{a}$ \\
\hline Quercetin & $9.36 \pm 0.25 \mathrm{a}$ & $6.18 \pm 0.22 \mathrm{~b}$ & $8.65 \pm 0.31 \mathrm{a}$ & $6.39 \pm 0.29 \mathrm{~b}$ \\
\hline Flavonols & $\mathbf{1 6 6 . 8 8 A}$ & $\mathbf{1 5 6 . 0 7 A}$ & $\mathbf{1 6 6 . 0 6 A}$ & $\mathbf{1 5 8 . 0 7 A}$ \\
\hline (+)-Catechin & $45.66 \pm 0.97 \mathrm{a}$ & $44.30 \pm 1.25 \mathrm{a}$ & $41.80 \pm 1.47 \mathrm{ab}$ & $38.76 \pm 1.39 \mathrm{~b}$ \\
\hline Dimer B2 & $10.62 \pm 0.25 \mathrm{a}$ & $10.20 \pm 0.29 \mathrm{a}$ & $8.33 \pm 0.27 \mathrm{~b}$ & $8.16 \pm 0.36 \mathrm{~b}$ \\
\hline (-)-Epicatechin & $13.53 \pm 0.32 \mathrm{c}$ & $17.99 \pm 0.56 \mathrm{c}$ & $30.25 \pm 1.41 \mathrm{~b}$ & $40.23 \pm 2.17 \mathrm{a}$ \\
\hline Flavan-3-ols & $\mathbf{6 9 . 8 1 B}$ & $\mathbf{7 2 . 4 9 B}$ & $\mathbf{8 0 . 3 9 A B}$ & $\mathbf{8 7 . 1 5 A}$ \\
\hline
\end{tabular}

*UV-C treatments: 0 - untreated sample (control); 60 - an hour of UV-C exposition; 120 - two hours of UV-C exposition; 180 - three hours of UV-C exposition. Means in the same row followed by the same letter are not significantly different at $p<0$. 05 according to Tukey test; \pm SD: standard deviation.

a clear tendency. The other identified compounds were not affected by UV-C radiation.

As with hydroxycinnamic acids and their derivatives, the amount of flavan-3-ols generally increased with UV-C exposure time. The results are presented in Table 4. However, considering each compound separately, only (-)-epicatechin increased, the amount of which, after three hours of irradiation, was three times higher than in the control. UV-C had a reductive influence on the content of $(+)$-catechin and dimer B2: their content decreased statistically after two hours of exposition.

\section{DISCUSSION}

In this preliminary investigation, the effect of UV-C light on yeasts (Saccharomyces cerevisiae) and bacteria (Oenococcus oeni) typically used in wine industry was studied. The study involved fermenting the must of 'Regent' grapes. The results showed that UV-C could be an efficient way of reducing the number of the microorganisms tested present in red wine made from the 'Regent' grape. When comparing the results of our laboratory-scale experiment to the findings of other authors, we reach similar conclusions. However, other authors ${ }^{3,5,14-15}$ have tested a different type of reactor, with a flow-rate capacity of $4000 \mathrm{~L} \mathrm{~h}^{-1}$. Keyser et al. ${ }^{\mathbf{1 4}}$ 
used UV-C radiation on different fruit juices (i.e. apple and orange juices, strawberry nectar) using two types of UV system: one (pilot scale) where the liquid flowed through a spiral tube equipped with a single UV lamp and one (commercial scale) using a series of $10 \mathrm{UV}$ lamps at UV dosages from 0 to $2066 \mathrm{~J} \mathrm{~L}^{-1}$. The authors' results showed that this method could successfully reduce the number of microorganisms; however, microbial counts after UV treatment were variable, depending on the liquid and UV dosage. Additionally, the resistance of bacteria, yeasts and moulds varied under the same treatment conditions. Fredericks et al. ${ }^{5}$ performed the experiment on grape juices and wines using a similar pilot-scale UV-C reactor system to that described by Keyser et al. ${ }^{14}$. The authors tested UV-C dosages from 0 to $3672 \mathrm{~J} \mathrm{~L}^{-1}$ (0-48 minutes) and concluded that the highest reduction of wine-related microorganisms was obtained under the highest UV-C dosage. Additionally, a $1377 \mathrm{~J} \mathrm{~L}^{-1} \mathrm{UV}-\mathrm{C}$ dose enabled reduction of approximately $98 \%$ and nearly $100 \%$ in individually inoculated Saccharomyces cerevisiae (initial count $1.07 \times 10^{6} \mathrm{CFU}$ $\mathrm{mL}^{-1}$ ) and Oenococcus oeni (initial count $2.24 \times 10^{5} \mathrm{CFU}$ $\mathrm{mL}^{-1}$ ), respectively, which is similar to the results we obtained in the hour-long treatment samples. Rizzotti et al. ${ }^{3}$ applied the UV-C treatment to different wines during winemaking on an industrial scale for the first time, using a commercial turbulent flow system where one pass of the liquid through the system took 15 minutes, giving a dose of about $1.0 \mathrm{~kJ} / \mathrm{L}$. In the case of red wines, this enabled minor microbial reduction (1-2 $\log \mathrm{CFU} / \mathrm{mL}$ ) of yeasts and bacteria; however, it did not influence qualities of the wine, such as the chemical and sensory properties. Lorenzini et al. ${ }^{\mathbf{1 5}}$ reported that different UV-C treatment times were needed to lower the microbial counts in red wines to a level below $1 \mathrm{CFU} / \mathrm{mL}$ in a reactor equipped with 40 germicidal lamps. Treatment ranging from 60 to 120 minutes was required to eliminate lactic acid bacteria, under an initial load of $2 \times 10^{4}$ and $3 \times$ $10^{3} \mathrm{CFU} / \mathrm{mL}$, respectively. Yeasts were eliminated after 120 and 160 minutes in Syrah and Valpolicella wines, respectively. However, 360 minutes of irradiation were necessary to decrease their viability to $\sim 10 \mathrm{CFU} / \mathrm{mL}$ in Barolo wine (initial load $2 \times 10^{3} \mathrm{CFU} / \mathrm{mL}$ ).

In general, UV-C radiation showed variable efficiency in microorganism inactivation, depending on the wine, colour and the microbial load ${ }^{3,5,15}$. Additionally, yeasts were found to be more resistant to UV-C light than lactic acid bacteria ${ }^{15-16}$.

In another study, by Falguera et al. ${ }^{17}$, UV-visible irradiation was tested as a technology to reduce the use of $\mathrm{SO}_{2}$ in white-wine manufacturing. The authors' results showed that UV-visible irradiation of must was effective in partially inactivating polyphenol oxidase and reducing volatile acidity (an indirect spoilage measure). Therefore, the authors concluded that this technology might be useful for reducing the amount of $\mathrm{SO}_{2}$ used in winemaking. However, a residual amount would be necessary, together with further optimisation of the irradiation process in terms of time and dose for each grape variety, and the equipment would need to be specified before its implementation.

Pala and Toklucu ${ }^{\mathbf{1 8}}$ subjected white and red grape juices to $\mathrm{UV}$ radiation using a coiled tube $\mathrm{UV}-\mathrm{C}$ reactor with nine lamps (each $28 \mathrm{~W}$ ). The initial total aerobic plate (AP) and yeasts and moulds (YM) counts of clarified red grape juice were 5.59 and $5.24 \log \mathrm{CFU} / \mathrm{mL}$, respectively. To eliminate microbial loads completely, two passes of the 3-L volume juice through the reactor were necessary ( $300 \mathrm{~s}$, flow rate $20 \mathrm{~mL} / \mathrm{s}, 25.2 \mathrm{~J} / \mathrm{mL})$. The effectiveness of microorganism inactivation by UV-C was highly affected by the red colour. The authors' previous study on the application of UV-C light to clarified pomegranate juice, which was 8.3 more abundant in monomeric anthocyanins than red grape juice, showed approximately a 41 and $45 \%$ lower reduction of AP and YM respectively, after one pass through the same reactor with a $12.5 \mathrm{~J} / \mathrm{mL} \mathrm{UV}-\mathrm{C}$ dose $^{19}$. Additionally, the microbial load of AP and YM in pomegranate juice was lower than in red grape juice.

Currently, the influence of UV-C radiation on the polyphenol profile of wine is not well studied. Our results show that, of the polyphenol compounds we detected, anthocyanins were most affected by UV-C radiation. With an increase in exposure time, a decrease in total anthocyanins, and of each compound separately, was noted. A similar decrease in the total amount of anthocyanins after UV-C radiation was noted by Matias et al. ${ }^{\mathbf{2 0}}$. On the other hand, Pala and Toklucu ${ }^{18}$ did not observe any significant changes in monomeric anthocyanin content after UV-C treatment with the reactor type described above. However, the authors found a relevant decrease in these compounds under thermal treatment at $85^{\circ} \mathrm{C}$.

Other authors have studied the effect of post-harvest UV-C application to grapes, and its influence on the phenolic compounds in fruits and their products. In a study by Pinto et al. ${ }^{21}$, the application of UV-C radiation enabled an increase in the content of individual anthocyanins, such as malvidin, delphinidin, peonidin and cyanidin, especially in conventional grapes. The authors concluded that UV-C light enabled the expression of genes related to the biosynthesis of phenolic compounds and, consequently, the greater accumulation of these metabolites. However, post-harvest UV-C treatment of fruits can result in lower anthocyanin and flavonol content in red wines ${ }^{22}$.

Our results show that among flavan-3-ols, (-)-epicatechin was the most affected by UV-C radiation. UV-C led to this compound increasing nearly three times after 180 minutes of exposure whereas a significant decrease in (+)-catechin and dimer B2 compounds was seen throughout the treatment. In turn, Pinto et al. ${ }^{\mathbf{2 1}}$ noted relevant enhancement of epicatechin and catechin concentrations in fresh 'Concord' grapes after UV-C exposure.

\section{CONCLUSION}

In this study, the effects of UV-C applied using an inner-irradiation-type reactor equipped with a low-pressure mercury lamp of $15 \mathrm{~W}(254 \mathrm{~nm})$ on the activity of yeast (Saccharomyces cerevisiae) and bacteria (Oenococcus oeni) in fermenting 'Regent' red grape juice and $\mathrm{NaCl}$ solution were determined. Furthermore, changes in the qualitative and quantitative composition of polyphenol compounds in 'Regent' must after UV-C exposure were evaluated. Hour-long treatment resulted in an approximately $99 \%$ reduction in yeasts (Saccharomyces cerevisiae) and bacteria (Oenococcus oeni); however this was not sufficient 
to eliminate microorganisms completely. Additionally, 60 minutes of UV-C exposure had no influence on the content in terms of several polyphenol compounds. In general, UV-C exposure affects polyphenol composition, especially by anthocyanin decomposition. However, no visible changes in the must colour were noted.

The effectiveness of the UV-C radiation on the viability of wine-related microorganisms in grape juice and wine depends on many factors. Further studies are required to optimise the process of inactivation, taking into account parameters such as the type of UV-C reactor, initial microbial load, species of microorganism, grape cultivar, as well as the colour and polyphenol profile. Additionally, it is important to obtain the best quality of the final product.

\section{CONFLICT OF INTEREST}

The authors declare that they have no competing interests.

\section{LITERATURE CITED}

1. Santos, M.C., Nunes, C., Saraiva, J.A. \& Coimbra, M.A. (2012). Chemical and physical methodologies for the replacement/reduction of sulfur dioxide use during winemaking: review of their potentialities and limitations. Eur. Food. Res. Technol. 234, 1-12. DOI: 10.1007/s00217-011-1614-6.

2. Machado, R.M.D., Toledo, M.C.F. \& Vicente, E. (2009). Sulphite content in some Brazilian wines: analytical determination and estimate of dietary exposure. Eur. Food. Res. Technol. 229(3), 383-389. DOI: 10.1007/s00217-009-1071-7.

3. Rizzotti, L., Levav, N., Fracchetti, F., Felis, G.E. \& Torriani, S. (2015). Effect of UV-C treatment on the microbial population of white and red wines, as revealed by conventional plating and PMA-qPCR methods. Food Control. 47, 407-412. DOI: 10.1016/j.foodcont.2014.07.052.

4. Du Toit, M. \& Pretorius, I.S. (2000). Microbial spoilage and preservation of wine: using weapons from nature's own arsenal-a review. S. Afr. J. Enol. Vitic. 21, 74-96.

5. Fredericks, I.N., Du Toit, M. \& Krügel, M. (2011). Efficacy of ultraviolet radiation as an alternative technology to inactivate microorganisms in grape juices and wines. Food Microbiol. 28(3), 510-517. DOI: 10.1016/j.fm.2010.10.018.

6. Salaha, M.I., Kallithraka, S., Marmaras, I., Koussissi, E. \& Tzourou, I. (2008). A natural alternative to sulphur dioxide for red wine production: Influence on colour, antioxidant activity and anthocyanin content. J. Food. Compos. Anal. 21, 660-666. DOI: $10.1016 /$ j.jfca.2008.03.010.

7. Franz, C.M.A.P., Specht, I., Cho, G.S., Graef, V. \& Stahl, M.R. (2009). UV-C-inactivation of microorganisms in naturally cloudy apple juice using novel inactivation equipment based on Dean vortex technology. Food Control. 20, 1103-1107. DOI: 10.1016/j.foodcont.2009.02.010.

8. Koutchma. T. (2009). Advances in ultraviolet light technology for non-thermal processing of liquid foods. Food Bioprocess Tech. 2, 138-155. DOI: 10.1007/s11947-008-0178-3.

9. Lu, G., Li, C., Liu, P., Cui, H., Yao, Y. \& Zhang, Q. (2010). UV inactivation of microorganisms in beer by a novel thin-film apparatus. Food Control. 21, 1312-1317. DOI: 10.1016/j. foodcont.2010.03.007.

10. Taze, B.H., Unluturk, S., Buzrul, S. \& Alpas, H. (2015). The impact of UV-C irradiation on spoilage microorganisms and colour of orange juice. J. Food. Sci. Tech. 52(2), 1000-1007. DOI: 10.1007/s13197-013-1095-7.

11. Islam, M.S., Patras, A., Pokharel, B., Wu, Y., Vergne, M. J., Shade, L., Xiao, H. \& Sasges, M. (2016). UV-C irradiation as an alternative disinfection technique: Study of its effect on polyphenols and antioxidant activity of apple juice. Innov Food Sci. Emerg. 34, 344-351. DOI: 10.1016/j.ifset.2016.02.009. 12. Samoticha, J., Wojdyło, A., Chmielewska, J. \& Oszmiański, J. (2016). The effects of flash release conditions on the phenolic compounds and antioxidant activity of Pinot noir red wine. Eur. Food Res. Technol. 1-9. DOI: 10.1007/s00217016-2817-7.

13. Mijowska, K., Ochmian, I. \& Oszmiański J. (2016). Impact of Cluster Zone Leaf Removal on Grapes cv. Regent Polyphenol Content by the UPLC-PDA/MS Method. Molecules. 21(12), 1688. DOI: 10.3390/molecules21121688.

14. Keyser, M., Műller, I. A., Cilliers, F.P., Nel, W. \& Gouws, P.A. (2008). Ultraviolet radiation as a non-thermal treatment for the inactivation of microorganisms in fruit juice. Innov Food Sci. Emerg. 9(3), 348-354. DOI: 10.1016/j.ifset.2007.09.002.

15. Lorenzini, M., Fracchetti, F., Bolla, V., Stefanelli, E., Rossi, F. \& Torriani, S. (2010). Ultraviolet light (UV-C) irradiation as an alternative technology for the control of microorganisms in grape juice and wine. In $33^{\text {rd }}$ World Congress of Vine and Wine, 8th General Assembly of the OIV (pp. 20-25).

16. Unluturk, S. \& Atilgan, M.R. (2014). UV-C Irradiation of Freshly Squeezed Grape Juice and Modeling Inactivation Kinetics. J. Food Process. Eng. 37(4), 438-449. DOI: 10.1111/ jfpe. 12099.

17. Falguera, V., Forns, M. \& Ibarz, A. (2013). UV-vis irradiation: An alternative to reduce $\mathrm{SO}_{2}$ in white wines? $L W T$ - Food Sci. Technol. 51, 59-64. DOI: 10.1016/j.lwt.2012.11.006. 18. Pala, Ç.U. \& Toklucu, A.K. (2013). Effects of UV-C light processing on some quality characteristics of grape juices. Food Bioprocess Tech. 6(3), 719-725. DOI: 10.1007/s11947-012-0808-7. 19. Pala, Ç.U. \& Toklucu, A.K. (2011). Effect of UV-C light on anthocyanin content and other quality parameters of pomegranate juice. J. Food Compos. Anal. 24(6), 790-795. DOI: 10.1016/j.jfca.2011.01.003.

20. Matias, F., Pinto, A.F., Torgal, I., Alves, M., Grácio, J. \& Mira, H. (2016). The Ultraviolet radiation (UV-C) for the microbiological stabilization of red wine. In BIO Web of Conferences 7, $39^{\text {th }}$ World Congress of Vine and Wine (Vol. 7, p. 02013). EDP Sciences. DOI: 10.1051/bioconf/20160702013. 21. Pinto, E.P., Perin, E.C., Schott, I.B., da Silva Rodrigues, R., Lucchetta, L., Manfroi, V. \& Rombaldi, C.V. (2016). The effect of postharvest application of UV-C radiation on the phenolic compounds of conventional and organic grapes (Vitis labrusca cv.'Concord'). Posthar. Biol. Technol. 120, 84-91. DOI: 10.1016/j.postharvbio.2016.05.015.

22. Cantos, E., Espín, J.C., Fernández, M.J., Oliva, J. \& Tomás-Barberán, F.A. (2003). Postharvest UV-C-irradiated grapes as a potential source for producing stilbene-enriched red wines. $J$. Agric. Food Chem. 51(5), 1208-1214. DOI: 10.1021/jf020939z. 